\title{
SOME THEORETICAL ASPECTS OF LANGUAGE LEARNING AND LANGUAGE TEACHING
}

\author{
David L. Wolfe \\ University of Michigan
}

\section{Part One: Preliminary Statements}

1.1 Differences and similarities between (a) the child's acquisition of his first language, (b) the child's acquisition of a second language, and (c) the adult's acquisition of a second language. The infant-child acquires his first language in the most natural or least artificial manner possible. There is normally nothing in his mind to prevent him from ultimately learning a native language; on the contrary, if Chomsky is correct in his 20th century version of the 16 th century notion of innate ideas, 1 the infant brain is predisposed towards the acquisition of the grammar of natural language. On the basis of his contacts with parole--the outer, surface manifestations of the speech of his home and community-and regardless of how fragmentary, uninventive, or degenerate this corpus may be, the child internalizes a highly complex, abstract set of interrelated systems, minimally a phonological system, a syntactic system, and a semantic system. Vygotsky ${ }^{2}$ has shown how the speech function and the thought function have two separate origins in the developing infant, speech having its roots in babbling and emoting through sound, and thought deriving from problem solving and the use of tools. Vygotsky concludes that apes are capable of both types of behavior, but that only human beings learn to fuse the two separate functions into a single use, i.e., that combination of vocalizing and thinking which leads to the creation of symbolic language and eventually to the formation of concepts. Vygotsky shows experimentally how the child's thinking develops from (a) an initial primitive mental organization of the environment into "heaps" or unorganized congeries through (b) several different types of thinking in complexes (still a primitive type of thinking) until it reaches in about the twelfth year of the child's life the final stage (c) where abstract concepts are understood and used.

lCf. N. Chomsky, Aspects of the Theory of Syntax, Cambridge, Mass., 1965, pp. 47-59 and N. Chomsky, Cartesian Linguistics, New York and London, 1966.

2In Lev S. Vygotsky, T'bought and Language, (translation by E. Hanfmann and G. Vakar), Cambridge, Mass., 1962. 
Once the child reaches this age of linguistic puberty and is capable of handling true concepts, he has completed the language learning cycle. This does not imply that he has stopped learning his native language; even if the lexicon of every language were not open-ended, as indeed it is, the child simply could not in a life-time of learning exhaust the lexical wealth of any language, nor could he put into actual practice the infinite possibilities available to him from the recursive devices of the syntax.

The notion of linguistic puberty is useful because it provides a natural linguistic dividing line between the child and the adult. The adult is aware (unconsciously, to be sure) of the nature and use of language in the sense that he has completed the language learning cycle, whereas the child, at any point in his linguistic development is still not linguistically mature. Furthermore, the adult has developed, in the course of his maturation, a general overall psychological consciousness equipped to deal in generalizations and abstractions as well as with linguistic concepts. This may explain in part why a child will quickly and accurately acquire a second language "unconsciously" from playmates in the street or from a nanny, whereas the same child may acquire only a very imperfect knowledge of a second language in many years of "conscious" classroom study. The adult, on the contrary, may through "conscious" drill acquire an excellent command of a second language, although the same adult, in a natural situation, such as that of an immigrant in an alien speech community, may acquire only a "broken," imperfect fluency after many years of natural exposure. It would appear that few adults can learn a language in the street and that few children can learn a language artificially. Although there may be elements acquired unconsciously by the adult in his learning of a (second) language and although there may be elements consciously learned by the child in his acquisition of a (second) language, broadly speaking, a child acquires a language (his first or a second) unconsciously and an adult learns a language consciously. Until the elementary classroom abandons adult "conscious" learning procedures and is converted into a more natural street-like situation, it will continue to be the case that adults in school learn languages much faster than children in school; and, since few adults retain the flexibility of mind required to acquire linguistic knowledge "unconsciously," the converse of this statement is also true: the child will learn a language much faster than the adult in a natural situation. Language acquisition by the adult is, then, an artificial process.

1.2 Language learning devices which run counter to the nature of language. The fact that language learning in the adult is an 
artificial process does not excuse the many practices common in language teaching today which run counter to the nature of true language behavior. The necessity for artificial language learning situations and techniques does not imply a corresponding necessity for distorting or changing the nature of what is being learned. Perhaps the most widespread textbook technique for needlessly increasing the artificiality of language learning in the adult is the use of drills and exercises which force the student to lie. In many classrooms up to $100 \%$ of the student's time is spent in the repetition of drill sentences such as these:

(a) Teacher:

Yesterday I went to the movies. play game

Last night

Last week

$$
\begin{gathered}
\text { Charles } \\
\text { etc. }
\end{gathered}
$$

(b) Teacher:

Mary studies every day. I

We

John work

etc.
Student:

Yesterday I went to the movies.

Yesterday I went to the play.

Yesterday I went to the game.

Last night I went to the game.

Last week I went to the game.

Last week Charles went to the game.

Student:

Mary studies every day.

I study every day.

We study every day.

We work every day.

John works every day.

These seemingly harmless sentences are, from the point of view of the real life situation of the teacher and the student, probably all untrue. From the point of view of true linguistic communication they border on the nonsensical; after all, who is referred to by "John" or "Charles" or "Mary"? Certainly no one in the environment of the teacher and the student. The evil in this type of repeated lying is that it produces a deadening effect in the mind of the student and reduces him to a parrot-like existence where repetition of form occurs in the vocal but repetition of meaning does not occur in the mind. This runs exactly counter to the insight into the nature of language provided by the great linguists of the last 100 years or so. Pike calls language a "form-meaning composite," 3 a unity which cannot be split up in theory and certainly not in practice. In this respect Pike follows Bloomfield, who states that "in language, forms cannot be separated from their meanings."4 Chomsky has

${ }^{3} \mathrm{~K}$. Pike, Language in Relation to a Unified Theory of the Structure of Human Behavior, Part I, Preliminary Edition, Glendale, Cal., 1954, p. 24.

${ }^{4}$ L. Bloomfield, "Meaning," Monatshefte für Deutschen Unterricht, 35, 1943, p. 102. 
characterized language as being "rule-governed creativity." 5 We are not engaged in language behavior unless we are expressing ourselves syntactically as well as semantically by saying what we want or need to say (the creative aspect) and, at the same time, saying it correctly (the rule-governed aspect). Humboldt has said that language "makes infinite use of finite means,"6 which is to say that there is no limitation on creativity (in Chomsky's sense) or meaning (in Bloomfield's sense), although the means, the grammar, Chomsky's rule-governed aspect and Bloomfield's form aspect, are finite, limited-in short, teachable and learnable. ("Teaching" in the present context refers to the contribution of the teacher and "learning" refers to that of the student; there is no single term in English for this process, thus forcing us to talk about language learning and/or language teaching. It is a single process, however, in which the teacher perhaps goes $50 \%$ of the way and the student the other $50 \%$ of the way. The teacher cannot put something into the student's mind without some degree of receptivity or cooperation on the part of the student, nor can the student learn a language completely on his own without any external stimulus or force.) One important way, then, in which adult language learning can be considerably improved is to eliminate from the classroom the necessity for continual lying. Only by talking factually about things and events inside and outside of the classroom will teachers and students really be engaged in true, undistorted language behavior, that is, in rule-governed creativity or in making infinite use of finite means. Part of the purpose of this paper, as well as seen below, is to show how this may be done.

Another common way in which the subject matter of elementary language courses is unnecessarily distorted is through the technique of memorized dialogs. If language behavior is rule-governed creativity, students reciting a memorized dialog are not engaged in language behavior, since there is no originality or creativity involved in this type of recitation; the student obviously does not in such a case express himself naturally. It might appear at first glance that the rule-governed aspect of language behavior does occur accurately in the recitation of a memorized dialog, but one must not be deceived into believing that because the student is producing, say, Spanish sentences without syntactic errors he has thereby internalized the syntax and the vocabulary he is displaying. The student will not be able to use the syntactic and lexical elements of a memorized dialog as part of his active linguistic corpus ${ }^{7}$ unless these elements

$5_{\mathrm{N}}$. Chomsky, "The Logical Basis of Lingustic Theory," Preprints of Papers for the Ninth Intemational Congress of Linguists, Cambridge, Mass., 1962, p. 512.

Guoted in Chomsky, Aspects, op. cit., p. 8.

${ }^{7}$ I use the word corpus in the sense expounded by Fries and Fries in Foundations for English Teaching, Tokyo, 1961. 
are thoroughly drilled as separate linguistic units. The fixed dialog does not necessarily provide a better or more natural context in which to learn lexical items. In this respect the single context of the fixed dialog is inferior to the multiple contexts of a drill or series of drills. Very little experience in the classroom is required to demonstrate this fact. One may indeed memorize the libretti of all of the operas of Verdi and still not be able to manage the rudiments of Italian grammar or be able to summon to one's aid a given lexical item buried in the context of a memorized dialog. It is true, of course, that there are certain formulas used in a speech community-greetings and farewells come under this categorywhich may be memorized as lexical units and drilled strictly as formulas. In general, however, the phonological, syntactic, and lexical units of a language will not be mastered outside of drill materials specifically designed to achieve such mastery. The use in the classroom of natural, unlimited, spontaneous dialogs that correspond to Chomsky's notion of rule-governed creativity will be dis cussed in Part Two, below.

A third common practice in the classroom which serves to undermine many of the goals of the language teacher is the failure on the part of the textbook writer and the teacher to distinguish between concrete sentences and abstract sentences in both drills and tests. Sentences such as

(c) Now I am standing up.

Now I am walking to the table.

Now I am picking up the red book.

I am not picking up the green book.

Now I am returning to my chair.

Finally, I am sitting down again.

are concrete, that is, of a very low level of abstraction in that they may be easily demonstrated or acted out in an immediate, visual, dramatic way. They can also be easily visualized in the student's mind on further repetition of the sentences with variations. These sentences refer to the immediate reality of the student-teacherclassroom situation and make use of realia or props that may be seen and handled and passed around. This is the most immediate and vivid use of language: reacting verbally and physically at the same time to objects and events in the surrounding environment.

On the other hand, sentences such as

(d) Where are you from?

I am from Toledo.

How old are you?

She is 23 years old. 
Where do you live?

Ask me where I live.

Tell me what your name is.

are not concrete in the same sense as the sentences in (c). No one of the sentences in (d) refers to objects in the immediate environment of the student. They all refer to more abstract information or facts that cannot be seen or handled in the same way in which a book or a pencil can be visualized and held. Nor can any of these statements be acted out dramatically so that the meaning becomes obvious to the beholder.

It is important for the language teacher to know that the use of sentences of type (c) makes possible the elimination from the classroom of the confusing and tedious technique of translation between the target and the native languages whereas the use of sentences of type (d) makes translation inevitable. Since sentences of type (c) can be demonstrated visually by acting on the part of the teacher and/or students, there is no necessity for their being translated into the native language of the student. In the first few weeks of a language course, the most crucial weeks of an entire course since here the student will establish a technique of learning, the teacher must avoid sentences of an abstract nature such as those quoted in (d). Only sentences of the lowest level of concreteness should be practiced if the teacher wishes to make the learning of the language less artificial. Translation as a learning technique means (a) operating in terms of the native language as a base from which one departs and to which one invariably returns and (b) considering the target language as a distant object of curiosity which acquires meaning only in terms of a recasting into the lexical and syntactic categories of the native language. If such a learning technique is employed, the target language acquires meaningful values, if ever, only after many years of language study and then usually by means of a year or two of practice abroad. This external approach to a language is not as natural as the internalizing approach which avoids translation and in so doing avoids the so-called interference of the native language. (The learning and teaching of translation as a skill is, of course, distinct from the unnecessary use of translation as a device for teaching the target language. The art of translation is probably best drilled after the native and target languages have both been independently mastered.)

In the later stages of language learning, when the student may be safely permitted to handle abstract sentences or sentences with a remote referent without the danger of resorting to the native language as a crutch, he must still be required to use his imaginative 
powers to the fullest in order to see or "feel" with maximum impact each sentence he utters. The normal, sophisticated, adult reaction to the sentence The dog bit the lady, for example, is to consider this information in the most abstract way possible, i.e., to focus one's intellectual attention on the abstract outline of the facts. The small child-or the poet for that matter, when he is functioning as a poet-would react to this sentence by seeing in his mind's eye the many details of color, size, and texture of the dog, of the woman, of her clothing, etc. This vivid exercising of the powers of the imagination must be explained and drilled in the classroom if the adult student is to realize the full potential of his language learning experience, that is, if he is to master the target language on its own terms and not in terms of so-called equivalents in the native language.

1.3 Contrastive analysis. A contrastive analysis is intended to reveal the degree to which two linguistic systems differ from each other as well as the extent to which they might overlap in structure. On the basis of such an analysis it is thought possible to predict a hierarchy of learning difficulties to be encountered by a native speaker of language $X$ learning target language $Y$. At all points in this systematic contrast where difficulties are likely to be encountered by the learner of $\mathrm{Y}$-whether they are phonological, syntactic or lexical-special and extensive drills must be constructed in order that the student may combat and overcome the interference caused by the powerful structural habits formed in learning the native language. According to this theory, the teacher need not necessarily contrast the two languages in the classroom as part of his teaching technique, but he will use materials based on the results of a contrastive analysis, and he will at all times be aware of the precise nature of the interference that continues to plague his students. In this way students will not spend too much time drilling what is assumed to be easy for them, but will devote most of their time to overcoming "real" problems.

It should he noted, however, that the target language itself may present interference. If, for example, students learning English have succeeded in mastering the difficult question patterns illustrated by the sentences

(e) Where does he live?

Where did he go?

What time is it?

When are they arriving?

What should I say?

then they will have difficulty producing included questions, as in the sentences 
(f) Can you tell me where he lives?

Do you know where he went?

Will you tell me what time it is?

I don't know when they are arriving.

Please tell me what I should say.

since the pressure resulting from a possible overlearning of the first set of structures will cause them to say

(g) *Can you tell me where does he live?

*Do you know where did he go?

*Will you tell me what time is it?

*I don't know when are they arriving.

*Please tell me what should I say.

which are all serious mistakes. Here is another example: If students have learned the structure underlying the sentences

(h) I want to study.

We need to work

They have to go.

You wish to stay.

this structure will interfere when they learn the structure underlying the sentences

(i) I must study.

We should work.

I can go.

They will stay.

causing them to say

(j) *I must to study.

*We should to work.

*I can to go.

*They will to stay.

which are wrong. It should be noted that such interference as is illustrated by the preceding examples is extremely common in language learning and does not have its origin in the native language, since the same mistakes occur regardless of the learner's language background. This indicates a serious weakness in any course materials based solely on contrastive analysis between the target and the native languages. Drilling contrasts within the target language, may turn out to be more significant to language teaching than merely drilling structures that contrast with certain structures of the native language. Thus, it is a serious technical error on the part of the teacher to explain the difference between the Spanish preterite form tomé and the Spanish present perfect form he tomado in terms of their English equivalents, $I$ took and $I$ have taken. The average 
student is not conscious of the linguistic analysis of his native language and in all probability cannot explain the difference in usage between the two English forms. The proper approach in the classroom in this case would probably be to ignore English and to explain the actual difference in point of view that is implied by the use of he tomado (which refers to an event occurring prior to the present moment in time, just as habré tomado-I will have taken-refers to an event occurring prior to a future moment in time and habia tomado refers to an event occurring prior to a past moment in time, regardless of whether or not the moment in time is actually expressed in any of these cases) versus the use of tomé (which includes the time period covered by he tomado and habia tomado, but without reference to any time-point-of-view). Once the various uses of each of these two tenses have been drilled and contrasted, and once the uses of both of these tenses have been contrasted in drills with each other, the learning job is completed and English equivalents are not only irrelevant, but, if needlessly introduced, possibly harmful.

Courses constructed according to the principle of contrastive analysis assume that the student will automatically, or with very little practice, transfer from his native language to the target language all that he can; this is not necessarily true. Once the student grasps the idea that the new language differs from his native language in many matters of structure, he will then not know when it is safe to operate in terms of his native language (it seldom is), and he may try to create his own structures on the basis of previous contact with the new language. Teachers of written and oral composition will be familiar with this type of interference. Some students, not knowing a correct form, will make up a form which does not parallel either the native or the target language. Or, a student will persistently fail to make a grammatical distinction in the target language which he actually does make consistently in his native language. These facts lend further weight to the proposition that teaching a foreign language primarily in terms of drills based on a contrastive analysis of the native and target languages with a strong emphasis on the differences between the two systems is not enough.

(There are many other factors which commonly interfere in the language learning process. Students who have studied a language other than the target or native languages will probably experience interference from the other foreign language, especially if the course they are currently taking is poorly designed. Certain students may suffer from psychological interference; many students are afraid to abandon their native language, even temporarily, in the fear that they could never operate in life solely on the bas is of a nother language. 
These students must learn to relax and to enjoy the game of using actively a new language system. Other students must contend with the interference of bad speech habits which they drilled under the influence of a textbook full of errors or under the influence of a non-native speaker of the target language who could not supply a native model, even a tape. Poor study habits play a large role in preventing smooth progress in language learning; many students believe they can learn a foreign language in large doses at infrequent intervals, whereas language learning is only achieved in small doses at frequent intervals.)

The important contrasts the learner of a new language should be required to master then, are those inherent in the system of the target language. If the native speaker of English, for example, can suspend his interest in English long enough to practice-at different times and in different contexts-the several uses of, say, Spanish tocar, tomar, and jugar until he can easily apply the proper word to the proper situation, he as well as his teacher need never actually become aware of the fact that these words represent a so-called problem in translation, i.e., that tocar and jugar are both translated as play, whereas tomar may be translated as drink or take. The problem of how to say play in Spanish has been eliminated by ignoring English completely and operating entirely in terms of natural Spanish contrasts within the system. Likewise, the problem of translating tomar into English need not arise as long as tomar is used in Spanish in the appropriate situations. The two Spanish verbs ser and estar, both often translated by English be, are supposed to constitute a problem for the English speaking student of Spanish. This problem disappears when each use of ser and each use of estar is properly drilled; the two verbs need never actually be drilled in contrast except for the necessary contrast between, e.g., esta flaco (he is skinny right now) and es flaco (he is a skinny person). The reason students of Spanish never or rarely make the mistake of saying *soy hablando instead of estoy hablando (I am speaking) is simply because they have been adequately drilled on this one particular use of estar with the gerund. Contrastive analysis between two languages, then, should be taught in a course in translation. In an elementary language course the important contrastive analysis that must be taught is the contrastive analysis of the linguistic units with in the target language. ${ }^{8}$

\footnotetext{
8 Many of the ideas set forth in this section were originally discussed in D. Wolfe, "Some Uses and Limitations of Contrastive Analysis in Teaching Foreign Languages," The Education Quarterly (University of the Philippines), XI, No. 3, 1963, pp. 19-22.
} 


\section{Part Two: The Minimal Stages Required in the Teaching of Language Elements to Adults}

2.1 Selection and ordering of linguistic units. Once the linguist has provided the language teacher with an adequate presentation of the elements and processes of a given natural language--including the recursive devices that underlie and explain the infinite surface forms of speech-the language teacher (or the textbook writer) must then break down the linguist's synthesis into a series of discrete elements, selecting out the elements to be included in a specific course of study, and ordering these elements into a pedagogically effective sequence. The selection of elements will be based on such criteria as frequency of occurrence of the linguistic element in speech or in literature (depending on the goals of the course), and the utility of the element in the classroom situation (a low frequency item may be particularly useful in the classroom).

For teaching purposes linguistic elements must be broken down maximally; if a single form has two or more meanings or uses, then it must be considered, from the standpoint of course design, as constituting two or more distinct units, each one of which will be drilled separately and perhaps at distant points in the course sequence. Similarly, if a single meaning or use is manifested in speech in two or more forms (as the imperfect tense is in Spanish, for example), then the linguistic element must be considered, in the course design, as two or more distinct elements to be drilled separately and perhaps at distant points in the course sequence.

Linguistic units may be phonological (a single allophone, for example, or a single meaningful intonation curve, or a letter of the alphabet), they may be lexical (any verb, noun, or adjective stem, for example), or they may be syntactic (a single ending or affix, for example, or a discontinuous form such as have -en, or a sentence type that constitutes a single unit of meaning, such as IF SUBJECT VERB-ED, SUBJECT WOULD VERB; this latter structure is a single linguistic unit used to refer to a hypothetical situation in the present or future time, as in these sentences: If I worked, I would earn money, If I studied I would learn, If I went to New York I would take a plane).

In practice it appears that the most effective classroom procedure is to introduce to the adult student a single linguistic unit at a time, drilling it as a distinct unit before drilling it in contrast with other similar units. It may turn out to be more appropriate to introduce two units in contrast with each other, and this can be done effectively in the classroom, but the presentation of more than two units at a time, such as a complete verb paradigm or a complete 
noun or pronoun declension, results in too much complexity for smooth, adequate learning on the part of the adult student.

2.2 Focus of attention on the linguistic unit. Since the adult learns a language consciously, at some point in the presentation of a linguistic element the student's attention must be focussed on the element itself in isolation from the rest of the sentence being repeated. This is usually done by repeating the element in isolation, by writing the abstract element-a sentence skeleton, for example-on the board, or by underlining in a sample sentence written on the board those parts which constitute the linguistic unit, as in the following example: Si Pepe tuviera dinero, pagaria la cuenta (If Pepe had money he wo $\overline{u l}$ pay the $\overline{b i l l}$ ). Here, the underlined elements constitute a linguistic unit which must be drilled. Such a focussing of attention on the linguistic unit to be explained and drilled is not necessary in teaching children, since they may acquire the unit without being conscious of it. The adult, however, requires the intellectual focus. Quite often the teacher himself needs to know intellectually exactly what it is that he is teaching. Focus of attention does not imply that a new linguistic unit cannot be introduced for the first time in a subtle, natural manner in the context of situations arising in the classroom; on the contrary, the ideal approach is to create a situation or make use of a naturally existing situation in order to introduce a new linguistic element. The teacher may then proceed naturally to the drill of this item. What is claimed here is merely that at some point, perhaps not until a post-drill review, the linguistic element should be, for the adult learner, focussed on in a conscious way. This may be done by inductive generalization on the part of the student himself.

2.3 Articulatory fluency in the item to be drilled. In an oral approach to the learning of a language a given linguistic unit may be repeated hundreds of times in the course of a series of drills. It is only logical to insist on a pronunciation check of the item to be drilled in advance of the drills. If a student is pronouncing an English $[\mathrm{h}]$ at the beginning of the Spanish word $h a$ as in $h a$ tomado (he has taken), giving this silent $h$ a foreign spelling pronunciation, and he continues to do this during hundreds of repetitions of this linguistic unit, then he will have acquired a habit difficult to break. Thus, a pronunciation check of the unit to be drilled must occur before (and during) the drills. This is not so important in connection with the substitution items in a drill, since these may be pronounced once and not repeated. 
2.4 Vitalization. The crucial concept of vitalization refers to the manner in which the meaning, the use, the practical utility, the application to reality of a linguistic unit is demonstrated, dramatized, explained or made vital and clear to the student. Vitalization is particularly important during the moment in which a new linguistic unit is introduced to the student, and it constitutes an essential element-the creative or meaningful element-in every learning stage that is to follow. No drill that is not vitalized will contribute much to the language learning process. Phonological elements are vitalized when a student perceives the humor in the phonemic difference between, say, He came by ship versus He came by sheep or when a wrong intonational pattern is used, as, say, in What are we having for dinner tonight-Mother? versus What are we having for dinner tonight, Mother? (with a rising intonation on Mother in the first, but not the second sentence). Vitalization is particularly important on the level of syntax; the precise use and time application of tense endings, for instance, must be demonstrated by the teacher and "felt" by the student. Lexical meanings are usually easier to vitalize than syntactic uses and phonological contrasts, but there still remains, regarding lexical items, the difficult problem of demonstrating exactly the range of meaning of a particular linguistic unit. $^{9}$

2.5 Repetition by the student (not by the teacher) of the linguistic unit being learned together with variation of all other elements in the sentences being repeated. The only way a linguistic unit may be learned in a single repetition is under conditions of extreme emotional stress. If a student were taught the meaning and pronunciation of a profane expletive, for example, and then the teacher proceded to slap the student's face until, enraged, the student used the swear word against the teacher, the student in this case would probably remember the item without the need for further repetition of it. The amount of repetition required to learn a linguistic unit is reduced proportionately according to the intensity of the emotion involved in the repetition. In most cases a considerable amount of repetition is required before a linguistic unit is mastered by the student. It is important that only the linguistic unit being drilled be repeated and that all other elements be varied; otherwise the student will wrongly associate a needlessly repeated element with the structure being learned. In some cases this is necessary

\footnotetext{
9The term vitalization, as applied to language learning is, to my knowledge, the invention of Professor Manoutchehr Varasteh of the University of Tehran; it was he who first illustrated to me the importance of this concept in language teaching.
} 
to a certain extent; that is, the teacher may want the student to as sociate a word such as yesterday with a past tense structure. But at some point in the drills the word yesterday should be changed to last night, last week, etc., so that the student will not assume that yesterday is part of the linguistic structure itself. It is of equal importance that the teacher not "give away" the linguistic unit in the cue sentences supplied to the student during the course of the drills; the student must always generate the structure on his own and no part of the structure should occur in the teacher's statements and questions that cue the student's response.

2.6 Forced transfer of attention from structural form to general meaning. In a drill the student will begin his uttering of sentences with attention focussed on the structure to be learned, but, if the drill is carefully constructed, in the course of the drill the student's attention will be shifted from the form of the structure itself to the total meaning of the sentence, especially the meaning of the lexical substitution items. This transfer of attention is achieved by a progressively more stimulating vitalization of the drill on the part of the teacher. The substitution items that appear in the teacher's questions and which will form part of the student's response must become increasingly more striking and attention-provoking so that the interest of the student will be drawn away from the mechanical form of the structure being practiced and placed entirely on the total meaning of the sentence. The actual moment in which the student begins to transfer his attention from the linguistic unit to the general meaning of the sentence being uttered is usually obvious to the teacher, since the student quite often will "break down" and fail to produce accurately the form of the linguistic unit being drilled. Thus, if the teacher says to a male student, in reference to the girl sitting next to him, "Are you going to invite Miss Wilson to the movies tonight?" expecting the response "No, but if I invited her, she would accept my invitation"(which practices the structure cited in 2.1, above: IF SUBJECT VERB-ED, SUBJECT WOULD VERB) and the student responds, "No, but if I would invite her, she accepted my invitation," the teacher may conclude-provided that the student has not made any mistakes previously in the drill-that the student has just shifted attention completely to the content of the utterance and is no longer thinking consciously about the syntax underlying the statement. The teacher must then continue drilling until the student succeeds in transferring his attention and at the same time produces the new structure correctly and unconsciously. In this type of exercise, learning actually occurs and the teacher may be certain that he has not wasted his or the student's time. 
This approach to drill is implied by Fries when he writes:

The adult need not repeat the slow processes of the child, when he attempts to learn a foreign language. Instead of the haphazard mixture of structural patterns that confront the child in the speech of those around him, in which the occurrence or the repetition of a particular pattern is a matter of chance, it is possible to have a series of practice exercises which begin with the fundamental structural patterns of the language, which provide sufficient repetition of each pattern to develop a habit, and which are arranged in such a sequence as to lead the student systematically through the whole range of devices which form the complicated structural machinery of a language. These structural exercises should in their content, as far as possible, have practical relevance to the circumstances or the situations in which the student is actually living in order that they may avoid artificiality and gain their meaning from immediate experience. ${ }^{10}$

Lado specifies these ideas of Fries in greater detail when he states:

Pattern practice-completely oral-is presented here as one such technique. It consists paradoxically in the conscious substitution of some element other than the chief element being taught so that primary attention is drawn away from it while the entire patterm is repeated!11 [Lado's italics]

By stressing the importance of varying all elements except the element to be learned (i.e., to be made unconscious, automatic), and by insisting that the teacher not reveal in his cue the form of the structure to be generated, I have merely attempted to refine the theoretical contributions of Fries and Lado in this respect.

2.7 Creative use of the linguistic unit in original dialogs. It will be noted that, thus far, the creativity of the student has been limited to responding to the teacher's linguistic stimulus; he has done this usually by answering questions affirmatively or negatively depending on the truth of the situation, or he has responded by supplying a missing word or two. It is now necessary for the student to become genuinely creative and to say, within the framework of the linguistic unit being drilled and the limitations of his vocabulary, what he wants to say. This is most conveniently accomplished by having students talk to each other in pairs, inventing questions and answers that practice the linguistic unit being learned. This

\footnotetext{
10C. Fries, Teaching and Learning English as a Foreign Language, Ann Arbor, 1945, p. 35. ${ }^{11}$ R. Lado, "Pattern Practice--Completely Oral," Selected Articles from Language Learning. No. 1, Ann Arbor, 1963, pp. 42-45.
} 
frees the teacher to circulate, eavesdrop, occasionally participate, and to spend some time with the slower learner, giving him what amounts to private tutoring.

2.8 Contrast drills. The linguistic unit being learned must now be drilled in contrast with other similar linguistic units. It is not possible to contrast each new linguistic item with all other elements in the language, but it is necessary, in order to show the relationship of the unit to other units, to drill it in contrast with other units of the same linguistic class. Thus, if the Spanish third person singular preterite ending for first conjugation verbs $(-\delta)$ has already been learned and the student is at present learning the corresponding first person ending $(-e)$, then, after this new ending has been learned, it must be contrasted with the third person ending, since both endings form part of a small linguistic subset of elements. The newly learned ending will also be drilled in contrast with any other tense endings that have been taught, such as, for example, the present indicative endings.

2.9 Creative contrastive use of the linguistic unit in original dialogs. This stage parallels 2.7, above, except that now the student must incorporate the new structure into the whole of his active corpus. The student must converse freely, drawing upon all that he has learned in the language, but his talk must refer to a situation also requiring the use of the newly learned element. This amounts to free conversation that relates to the new linguistic unit.

2.10 Testing. The student may now be tested on the linguistic unit under consideration (in contrast, of course, with all previously learned linguistic units). It is beyond the scope of the present article to discuss methods of testing; the reader is referred to $\mathrm{R}$. Lado, Language Testing: the construction and use of foreign language tests (London, 1961) and R. Valette, Modern Language Testing (New York, 1967. 